\title{
MACROPRUDENTIAL STRESS-TESTING THE INDONESIAN BANKING SYSTEM USING THE CREDIT RISK MODEL
}

\author{
Shilvia Kurniawati* and Deddy Priatmodjo Koesrindartoto ${ }^{* *}$ \\ *School of Business and Management, Bandung Institute of Technology, Ganesha 10, Bandung, Indonesia. \\ Email: shilvia_kurniawati@sbm-itb.ac.id \\ "School of Business and Management, Bandung Institute of Technology, Ganesha 10, Bandung, Indonesia. \\ Email: deddypri@sbm-itb.ac.id
}

\begin{abstract}
This study implements a macroprudential stress test and develops the Economic Risk Weighted-Capital Adequacy Ratio (ERW-CAR) to evaluate the resilience of the Indonesian banking sector. The results show that the historical and one-year ahead predicted ERW-CARs are currently three percent lower than the Indonesia regulatory $\mathrm{CAR}$, and continue to decrease by nearly two percent following an exchange rate shock. However, the capital adequacy requirement stands above the eight percent threshold and the banks are still able to optimize their capital allocation.
\end{abstract}

Keywords: Stress test; Credit risk; Macroprudential supervision.

JEL Classifications: G21; G28; E58.

\author{
Article history: \\ Received : July 01, 2019 \\ Revised : : September 14, 2019 \\ Accepted : February 24, 2020 \\ Available online : February 29, 2020 \\ https://doi.org/10.21098/bemp.v23i1.1093
}




\section{INTRODUCTION}

Assessing vulnerability of individual financial institutions and the entire financial sector-from microprudential and macroprudential perspectives-to adverse macroeconomic events is crucial to fostering financial stability. Stress-testing is one of the main practical tools in macroprudential policy. In Indonesia, the International Monetary Fund's Financial System Stability Assessment documented the result of stress-tested banks for the years 2010 and 2017 (Otoritas Jasa Keuangan, 2016a). These reports show that Indonesia's macroeconomic performance has been robust and the financial system has been stable (see also, Allmen \& Hamann, 2017).

Recently, the central bank of Indonesia has implemented a top-down stress-testing practice as a process of macroprudential supervision with expert judgement, which aimed to evaluate the resilience of the systemic financial sector to major shocks to macroeconomic scenarios, such as a negative shock to Gross Domestic Product (GDP) and a shock to the exchange rate. The implementation of the stress test has, thus far, been focused on the commercial banking sector, since it plays the largest role in the Indonesian financial system. The commercial banking sector represents $69.75 \%$ of the market share of all financial firms, indicating that it is the greatest contributor to the financial system in Indonesia.

Studies on banking stress tests in Indonesia are limited to the impact of economic conditions on credit risk. Indra (2018), for example, explored stresstesting analysis of conventional and Sharia banking credit portfolios in Indonesia using Non-Performing Loans (NPL) and Non-Performing Financing (NPF) as the credit risk indicators. The author simulated the stress test scenarios by comparing the performance of the two credit risk indicators with macroeconomic shocks.

We implement a macroprudential stress test. First, we establish a macroeconomic scenario design based on a Indonesia-specific macroeconomic model and investigate not only the predicted normal scenario but also the predicted severe scenario. This allows us to obtain outcome indicators that consider both systemic and idiosyncratic risks as outlined in the work of Buncic and Melecky (2013). Our study contributes to the literature in the following ways. First, it does not only account for the systemic risk in the banking sector in general, it also accounts for the risk emanating from the risk profiles of banks' business activities at the bank level. Second, our study improves the performance of stress tests based on the signals from loan growth as a credit risk indicator to changing macroeconomic conditions as suggested by Onder, Damar, and Hekimoglu (2016). We do so by including an equity index - an approach consistent with Fiori, Foglia, and Iannotti (2009). Principally, our study does not only construct a macroprudential stresstesting framework for Indonesian commercial banks but also develops the main indicator outcome of the stress test after considering economic risks, called ERWCAR.

Our results show that, among the economic risks analysed, exchange rate depreciation is the most important determinant of loan performance in the banking system. More interestingly, the results from the ERW-CAR under historical and predicted normal scenarios decline below the regulatory CAR. This means that when economic risks are properly considered, Indonesian banks optimize their capital allocation. The results from the stress scenario indicate that aggregate Indonesian banks' capital buffer is still strong enough to withstand severe exchange rate shocks and meets the $8 \%$ minimum capital adequacy requirement. 
This paper unfolds as follows. Section II presents the stress-testing framework. Section III details the methodology. Section IV analyses the results and Section V outlines the conclusion.

\section{STRESS-TESTING FRAMEWORK}

A stress test is commonly performed through the following procedure: designing macroeconomic scenarios; linking macroeconomic conditions to the risk indicators and exposures, such as credit, market, and liquidity risk factors; and analyzing risks to outcome indicators. To generate macroeconomic scenarios, a baseline scenario is constructed to capture the current macroeconomic condition and a stress event is created to simulate the extreme but plausible macroeconomic situation. Regarding the approach of the scenario design, expert judgement and the modelbased approach can be employed to construct the macroeconomic scenarios.

Practically, a macroeconomic model to establish a baseline scenario is based on either forecast or historical macroeconomic conditions. Meanwhile, a stress model scenario is constructed by one or ninety percentile distribution of a one-year-ahead forecast (Buncic \& Melecky, 2013). To ascertain the forecast value, three modelbased methods are often constructed in the credit risk stress-testing analysis, such as a structural econometric approach, a Vector Autoregressive (VAR) model, and a statistical model (Foglia, 2009). However, central banks in emerging countries typically employ their expert judgement due to the unavailability of extensive historical data to estimate the model-based specifications (Melecky \& Podpiera, 2012).

Since the credit-related global financial crisis in 2008, credit risk has become a risk factor that is sensitive to the macroeconomic condition. Credit risk is related to loan quality, and is frequently approximated by using loan performance measures as dependent variables. Such loan performance measures are default rates (Alessandri, Gai, Kapadia, Mora, \& Puhr, 2008; Castrén, Dées, \& Zaher, 2008; Coletti, Lalonde, Misina, Muir, \& St-amant, 2008; Fiori et al., 2009), loan loss provision (Lehmann \& Manz, 2006), nonperforming loans (Buncic \& Melecky, 2013; Cihák, 2007; Melecky \& Podpiera, 2012), and loan growth (Onder et al., 2016). For the independent variables, the most frequently used are inflation rate, exchange rate, lending rate, GDP growth, and equity return (Foglia, 2009).

These macroeconomic variables are mapped to loan performance before measuring the PD and Loss Given Default (LGD). In terms of a credit risk model, the PD and LGD can be measured following the Quantitative Impact Study (QIS) as cross-country benchmarks (BIS, 2006). Then, banks' risk exposures, especially the credit risk exposure, are considered to check the potential effect of the analyzed risk factors through Exposure at Default (EAD) in stress-testing practices.

Finally, the outcome indicators, as the output of stress-testing exercises, need to be applicable to the macroprudential policy. One of such indicators is Expected Loss (EL), which is used to assess the credit losses on bank loan portfolios under macroeconomic stressed events. Another outcome indicator is the CAR. The Basel Committee suggests that the system-wide CAR should remain above the eight per cent threshold to reach the minimum core capital for banks.

From the aforementioned studies, it can be seen that stress tests are carried out using a very comprehensive modelling framework by not only looking at the 
impact of various macroeconomic shocks on credit risk variables but also providing output indicators. Therefore, we follow the recent literature by presenting an applicable outcome indicator, CAR, in addition to the forecast shock scenario based on an Indonesia-specific macroeconomic model.

\section{METHODOLOGY}

\section{A. Macroeconomic Scenarios}

The first component of the stress test, from the macroprudential perspective, typically requires the development of the baseline and macroeconomic stress scenarios. We employ the through-the-cycle scenario as proposed by Buncic \& Melecky (2013), and based on a time-series arithmetic mean of each macroeconomic variable over a long period of time to obtain an average value from the first observation of the scenario. The macroeconomic variables of interest comprise GDP growth, inflation rate, lending rate, exchange rate, and change in the monthly equity price from the period of January 2004 to December 2018. All data are retrieved from the Special Data Dissemination Standard of the central bank of Indonesia (Bank Indonesia), Indonesian Banking Statistics (IBS), and Federal Reserve Economic Data. The data are calculated based on year-over-year change.

The second observation, called a baseline scenario, results from a predicted value of every macroeconomic variable by forecasting the model one-year into the future. The following is a VAR model with $\mathrm{k} \operatorname{lag}(\mathrm{s})$

$$
\begin{gathered}
Y_{t}=c+\sum_{i=1}^{k} \alpha_{1, i} I R_{t-i}+\sum_{i=1}^{k} \alpha_{2, i} L R_{t-i}+\sum_{i=1}^{k} \alpha_{3, i} E R_{t-i}+\sum_{i=1}^{k} \alpha_{4, i} G D P_{t-i} \\
+\sum_{i=1}^{k} \alpha_{5, i} E P_{t-i}+U_{t}
\end{gathered}
$$

where $Y_{t}$ is a vector of dependent variables containing five macroeconomic variables, namely GDP growth $\left(G D P_{t}\right)$, Inflation Rate $\left(I R_{t}\right)$, Lending Rate $\left(L R_{t}\right)$, Exchange Rate $\left(E R_{t}\right)$, and change in Equity Price $\left(E P_{t}\right)$ at time period $t$. In terms of GDP growth, we first compute the linear interpolation of the seasonally adjusted GDP index. For the lending rate, the change results from averaging three kinds of lending rates, comprising investment, consumption, and working capital. Regarding independent variables, all macroeconomic variables are set at the time period $t$-i. The $U_{t}$ is a multivariate normal vector of disturbances with zero mean and variance-covariance matrix $\sum_{u}$.

One year ahead point forecasts are calculated as the iterated twelve period forecasts from the monthly $Y_{t}$ series, using the recursive forecast equation below

$$
\begin{aligned}
& Y_{t+1}=c+\alpha_{1, i} I R_{t}+\alpha_{2, i} L R_{t}+\alpha_{3, i} E R_{t}+\alpha_{4, i} G D P_{t}+\alpha_{5, i} E P_{t}+U_{t+1} \\
& \vdots \\
& Y_{t+h}=c+\alpha_{1, i} I R_{t+h-1}+\alpha_{2, i} L R_{t+h-1}+\alpha_{3, i} E R_{t+h-1}+\alpha_{4, i} G D P_{t+h-1} \\
& +\alpha_{5, i} E P_{t+h-1}+U_{t+1}
\end{aligned}
$$


where $h$ is the number of steps ahead in the forecast. Finally, a one-year forecast value of $Y_{t+h}$ can be obtained from iterating twelve-step forecasts for every monthly macroeconomic variable of interest.

The third observation is to construct a stress condition of every macroeconomic variable from the forecast distribution. The future stress value results from the left (right) tail distribution of the forecast, considering the macroeconomic variable. For example, we set one left percentile for GDP growth or one right percentile for lending rate. This can be the same as $(1-\alpha) 100 \%$ forecast confidence interval, where $\alpha$ is 0.99 for one percentage of left (right) distribution.

\section{B. Credit Risk Model and Predicted Loan Growth}

The second component of the macroprudential stress test is linking the macroeconomic scenario to the risk factor, and selecting the credit risk factor as the main risk factor. Following Onder et al. (2016), we also estimate a Loan Growth $(L G)$ regression that incorporates the five macroeconomic variables, namely Inflation Rate $(I R)$, Lending Rate $(L R)$, Exchange Rate $(E R)$, GDP growth $(G D P)$, and change in Equity Price $(E P)$ at time period $t+1$. The descriptive statistics of the credit risk and macroeconomic variables are summarized in Appendix 1. We estimate the following loan growth regression using aggregate monthly data from January 2004 to December 2018.

$$
L G_{t+1}=c+\rho L G_{t}+\beta_{1} I R_{t+1}+\beta_{2} L R_{t+1}+\beta_{3} E R_{t+1}+\beta_{4} G D P_{t+1}+\beta_{5} E P_{t+1}+\varepsilon_{t+1}
$$

The use of loan growth regression is to transmit the relationship between the economic situation through the macroeconomy and the banking system. In turn, the magnitude of the coefficient estimate of each macroeconomic variable will influence the future value of loan growth in both the predicted normal and stress scenarios. Consistent with Buncic \& Melecky (2013), we calculate the one-period ahead loan growth as follows

$$
L G_{t+1}^{P, S}=(F V-H V) * \text { coefficientestimate }
$$

where $L G_{t+1}^{P, S}$ is the value of loan growth at time period $t+1$, one-year ahead in the predicted normal $P$ and stress $S$ observations. The two future values are calculated by subtracting future (normal or stress) from historical values of macroeconomic variables, denoted as $F V$ and $H V$, respectively, and multiplting the result by the coefficient estimate. The bigger the coefficient estimate, the larger the impact of the change in loan growth.

\section{The Systemic Component of Credit Risk}

Focusing on the credit risk factor, exposure to distinct risk factors is calculated as a distinct macroprudential stress test component. Similar to Buncic \& Melecky (2013), we determine the PDs under two scenarios $\left(P D_{i}^{P, S}\right)$ by using the effect of 
credit risk (loan growth) in this paper. This is a prior calculation of loan growth, based on historical PDs $\left(P D_{i}^{H}\right)$ available in the fifth Quantitative Impact Study (QIS 5) from the Bank for International Settlements (BIS). We, then, weighted these historical PDs using the average rate of all classes, denoted as $\frac{P D_{i}^{H}}{\overline{P D}^{H^{\prime}}}$, as a given
weight of the macroeconomy impact.

$$
P D_{i}^{P, S}=\emptyset+L G_{t+1}^{P, S} * \frac{P D_{i}^{H}}{\overline{P D}^{H}}+P D_{i}^{H}
$$

All PDs are calculated based on seven asset classes $i$, consisting of corporates, Small and Medium-sized Enterprises (SMEs), consumer mortgage loans, consumer loans, other consumer loans, sovereigns and banks (BIS, 2006). The $\varnothing$ parameter shows the proportion between the changes in loan growth and PDs. Practically, one can consider values in the 0.6-1.0 range depending on the $t$-day overdue loans. Indonesian commercial bank loans are empirically classified as defaulted loans if overdue above 90 days ( $90 \%$ or 0.9 overdue), according to Peraturan Bank Indonesia No. 7/2/PBI/2005 (Gubernur Bank Indonesia, 2005).

\section{The Grouped Banks' Component of Credit Risk}

Since the lending practices can vary depending on the risk profiles of the bank groups, we calculate the PDs on seven asset classes $i$ at grouped banks $j$ under three scenarios, denoted as $P D_{i, j}^{H, P, S}$. Based on POJK6/2016, banks in Indonesia are grouped into four business activities (known as BUKU), which are classified based on the amount of the core capital as follows (Otoritas Jasa Keuangan, 2016b).

(1) BUKU 1: less than one trillion rupiah

(2) BUKU 2: from one to less than five trillion rupiah

(3) BUKU 3: from five to less than thirty trillion rupiah

(4) BUKU 4: at least thirty trillion rupiah

$$
P D_{i, j}^{H, P, S}=P D_{i}^{H, P, S}+\left\{\begin{array}{cc}
k \times \frac{C G_{i, j}-\operatorname{med}\left(C G_{i}\right)}{\max \left(C G_{i}\right)-\operatorname{med}\left(C G_{i}\right)} & \text { if } C G_{i, j}>\operatorname{med}\left(C G_{i, j}\right) \\
0 & \text { otherwise }
\end{array}\right.
$$

Following Buncic \& Melecky (2013), the results of the $P D_{i, j}^{H, P, S}$ are derived from the summation between the value of $P D_{i}^{H, P, S}$ in the historical $H$, predicted normal $P$ and stress $S$ observations represented by the formula above. The values are determined based on formal computation. Also, the rate of $C G_{i, j}$, as annual credit growth of banks with asset class $i$ at business activities-specific banks $j$ before the latest period of positive credit growth, describe the level of aggresive lending (Jimenez \& Saurina, 2006). 
If the $C G_{i, j}$ is greater than the medium credit growth under asset class $i$, $\operatorname{med}\left(C G_{i}\right)$, then the $k$ parameter as control penalty between $P D_{i}^{H, P, S}$ and $P D_{i, j}^{H, P, S}$ will influence the $P D_{i, j}^{H, P, S}$ values. This means that there is an effect originating from the business activities component that is transferred to the systemic component. Conversely, if the $C G_{i, j}$ is at and smaller than the $\operatorname{med}\left(C G_{i}\right)$, then the $P D_{i, j}^{H, P, S}$ values are only affected by the systemic component of credit risk.

The $k$ parameter under three scenarios differs (Buncic \& Melecky, 2013) at 5\%, $10 \%$ and $20 \%$ for historical, predicted normal, and stress scenarios, respectively. If the $C G_{i, j}$ is more than the med $\left(C G_{i}\right)$, this parameter will be amplified by the computation of $\frac{C G_{i, j}-\operatorname{med}\left(C G_{i}\right)}{\max \left(C G_{i}\right)-\operatorname{med}\left(C G_{i}\right)}$, where the maximum credit growth under asset class $i$ is denoted as $\max \left(C G_{i}\right)$.

Another measure of credit risk as the main input of the capital computation is losses given default (LGDs). Following Buncic \& Melecky (2013), the LGDs of the seven asset classes $i$ at grouped banks $j$ under historical $H$, predicted normal $P$, and stress $S$ scenarios, $L G D_{i, j}^{H, P, S}$ are calculated as

$$
L G D_{i, j}^{H, P, S}=L G D_{i}^{H} \times\left(\frac{P D_{i, j}^{H, P, S}}{P D_{i}^{H}}-1\right) \times \rho_{L G D, P D}+L G D_{i}^{H}
$$

where the LGDs on asset class $i$ under historical scenario $H$, denoted as $L G D_{i}^{H}$, are available from the QIS 5. The $L G D_{i, j}^{H, P, S}$ values are also influenced by the $\rho$ parameter to control the relation between PDs and LGDs that range from $10 \%$ to $20 \%$ under historical and predicted normal observations. The $\rho$ parameter itself increases by around $30 \%-50 \%$ if observed during a period of crisis (Altman, Resti, \& Sironi, 2002).

\section{E. Output Indicators}

The last component of the macroprudential stress test is estimating the outcome indicators, which consist of expected losses, net losses, and CAR. Following Buncic \& Melecky (2013), the magnitude of CAR in this study also integrates the economic risks from changing macroeconomic conditions known as ERW-CAR.

To compute the ERW-CAR, we need the number of net losses based on three scenarios to obtain historical and predicted observations in the normal and stress condition one-year into the future. The computation is as follows

$$
\begin{aligned}
& E L_{i, j}^{H, P, S}=P D_{i, j}^{H, P, S} \times L G D_{i, j}^{H, P, S} \\
& \operatorname{NetLoss}_{j}^{H, P, S}=\sum_{i=1}^{7} E L_{i, j}^{H, P, S}-\left(\text { Reserve }_{j}+\text { Profit }_{j}^{H, P, S}\right) \\
& E R W-\text { CAR }^{H, P, S}=\frac{\text { RegCap }- \text { NetLoss }^{H, P, S}}{\text { RiskWeighted Asset }}
\end{aligned}
$$


where the expected losses of the seven asset classes $i$ at grouped banks $j$ under three scenarios, $E L_{i, j}^{H, P, S}$, come from the product of $P D_{i, j}^{H, P, S}$ and $L G D_{i, j}^{H, P, S}$. The net losses are calculated in the level of grouped banks $j$ under three observations, $\operatorname{NetLoss}_{j}^{H, P, S}$, since the amount of loan loss reserves and profits, denoted as Reserve $_{j}$ and Profit ${ }_{j}^{H, P, S}$, respectively, can be collected in the group of business activities specific to banks (see Appendix 2). However, we can also calculate the NetLoss ${ }^{H, P, S}$ using aggregate data, depending on data availability.

Notably, the profits can be computed under historical $H$, predicted normal $P$, and stress $S$ scenarios. We may choose to follow the stress tester assuming that the profit amount is zero under predicted normal and stress condition, meaning that banks do not have any profit in the future. Further, the regulatory capital (RegCap) and Risk-Weighted Asset (RWA) can be calculated at the level of the banking system (see Appendix 2), so we can obtain the amount aggregate $E R W-C A R^{H, P, S}$ under historical $H$, predicted normal $P$, and stress $S$ observations.

\section{RESULTS}

\section{A. Macroeconomic Scenarios}

To predict the macroeconomic variables, VAR method is a typical method used in the time series literature. To apply this method, the variables should pass the stationarity condition using unit root tests (the Augmented Dickey-Fuller test, in this paper). The parameter estimates of five VAR models are represented in Table 1 below.

\section{Table 1.}

\section{VAR Results}

This table shows the results of Vector Autoregression estimation, with five macroeconomic variables used are inflation, lending rate, exchange rate, GDP, and equity price from January 2004 to December 2018. The selected variables are defined as follows: (i) Inflation Rate, $I R$, computed by the change during the past twelve months; (ii) Lending Rate, $L R$, measured by the average of working capital, consumption and investment lending rate; (iii) Exchange Rate, ER, computed by the natural log of the national currency to US dollar spot exchange rate for Indonesia; (iv) GDP Growth, GDP, computed by the natural log of the seasonally adjusted GDP index with linear interpolation; and (v) Equity Price, $E P$, measured as as the natural log of the ${ }^{\wedge} \mathrm{JKSE}$ stock price. All selected variables are in year-over-year change. The auto selection lag by SBIC is 2 and adjustment to heteroskedasticity and autocorrelation in residual done using the Newey and West (1987) standard errors starting with a maximum of 3 lags. The statistical significance at the $1 \%$, $5 \%$, and $10 \%$ levels are denoted by ${ }^{* * *}, * *$, and ${ }^{*}$, respectively. The $t$-statistics are reported in parenthesis.

\begin{tabular}{lcccccc}
\hline $\begin{array}{l}\text { Dependent } \\
\text { Variable }\end{array}$ & & $\boldsymbol{I R}_{t-i}$ & $\boldsymbol{L} \boldsymbol{R}_{t-i}$ & $\boldsymbol{E \boldsymbol { R } _ { t - i }}$ & $\boldsymbol{G D P _ { t - i }}$ & $\boldsymbol{E P}_{t-i}$ \\
\hline \multirow{4}{*}{$I R_{t}$} & $\alpha_{1}$ & $1.0117^{* * *}$ & 0.0395 & 0.0065 & -1.5780 & -0.0065 \\
& & $(15.21)$ & $(0.10)$ & $(0.35)$ & $(-1.51)$ & $(-0.72)$ \\
& $\alpha_{2}$ & -0.0836 & -0.0763 & 0.0143 & 1.4975 & $0.0224^{* * *}$ \\
& & $(-1.33)$ & $(-0.23)$ & $(0.69)$ & $(1.53)$ & $(2.90)$ \\
& & 0.0152 & $1.3810^{* * *}$ & -0.0023 & $-0.1851^{*}$ & $-0.0038^{* *}$ \\
& $\beta_{1}$ & $(1.48)$ & $(17.33)$ & $(-0.77)$ & $(-1.91)$ & $(-2.25)$ \\
& & 0.0021 & $-0.4504^{* * *}$ & 0.0032 & $01620^{*}$ & 0.0024 \\
& $\beta_{2}$ & $(0.22)$ & $(-6.23)$ & $(0.93)$ & $(1.82)$ & $(1.44)$ \\
& & -0.1702 & -2.5046 & $0.8799^{* * *}$ & $-8.2565^{* * *}$ & -0.1025 \\
$E R_{t}$ & $\gamma_{1}$ & $(-0.51)$ & $(-1.12)$ & $(7.74)$ & $(-2.87)$ & $(-1.44)$ \\
& & 0.2683 & 1.6616 & -0.0327 & $7.4789^{* * *}$ & 0.0863 \\
& $\gamma_{2}$ & $(0.88)$ & $(0.79)$ & $(-0.29)$ & $(2.78)$ & $(1.24)$ \\
\hline
\end{tabular}


Table 1.

VAR Results (Continued)

\begin{tabular}{lcccccc}
\hline $\begin{array}{l}\text { Dependent } \\
\text { Variable }\end{array}$ & & $\boldsymbol{I R _ { t - i }}$ & $\boldsymbol{L} \boldsymbol{R}_{t-i}$ & $\boldsymbol{E R _ { t - i }}$ & $\boldsymbol{G D P _ { t - i }}$ & $\boldsymbol{E P _ { t - i }}$ \\
\hline \multirow{4}{*}{$G D P_{t}$} & $\delta_{1}$ & 0.0157 & -0.0094 & 0.0011 & $1.6241^{* * *}$ & $0.0024^{*}$ \\
& & $(0.96)$ & $(-0.16)$ & $(0.33)$ & $(17.95)$ & $(1.80)$ \\
& $\delta_{2}$ & -0.0141 & 0.0062 & -0.0022 & $-0.6916^{* * *}$ & $-0.0020^{*}$ \\
& & $(-0.87)$ & $(0.12)$ & $(-0.76)$ & $(-7.82)$ & $(-1.77)$ \\
$E P_{t}$ & $\omega_{1}$ & $-1.2640^{* *}$ & 4.0598 & 0.1720 & $15.3145^{* * *}$ & $1.1934^{* * *}$ \\
& & $(-2.18)$ & $(0.80)$ & $(0.68)$ & $(2.77)$ & $(9.86)$ \\
& $\omega_{2}$ & 0.7899 & -2.1284 & 0.0174 & $-14.1537^{* * *}$ & $-0.2089^{*}$ \\
& & $(1.55)$ & $(-0.48)$ & $(0.08)$ & $(-2.69)$ & $(-1.92)$ \\
\hline
\end{tabular}

Table 1 shows that at least, one independent variable is significant at $1 \%$ level, meaning that there is a relationship between the dependent and, at least, one independent variable. To ensure the validity of the model, we examine its performance in Table 2 below.

Table 2.

\section{VAR Performance}

This table shows the performance of the VAR model with five macroeconomic variables, namely inflation, lending rate, exchange rate, GDP, and equity price from January 2004 to December 2018. The $R$-squared of all macroeconomic variables are measured in decimals.

\begin{tabular}{lccc}
\hline Macroeconomic Variable & $\boldsymbol{R}$-squared & $\boldsymbol{F}$ & $\boldsymbol{P} \boldsymbol{P}$ \\
\hline Inflation & 0.9137 & 318.6491 & 0.0000 \\
Lending rate & 0.9867 & 1310.199 & 0.0000 \\
Exchange rate & 0.8610 & 151.2170 & 0.0000 \\
GDP & 0.9745 & 770.7524 & 0.0000 \\
Equity Price & 0.9205 & 271.7483 & 0.0000 \\
\hline
\end{tabular}

Table 2 shows that the VAR model is valid and can be used to recursively forecast and obtain the predicted values of the macroeconomic variables, as indicated by the large $R$-squared of all the specifications. After iterating twelvemonth forecasts from each macroeconomic variable to obtain the predicted value, the stress value can also be determined based on the left or right-tail probability, ranging from $1 \%$ to $10 \%$ for the standard normal distribution to define the stress condition.

Column 2 of Table 3 shows that historically inflation change by $6.11 \%$, lending rate change by $-0.46 \%$, exchange rate change by $3.39 \%$, GDP growth by $5.38 \%$, and equity return by $16.58 \%$. These values can be a reference point of each macroeconomic condition, since they are calculated from an equilibrium state and covered economic cycles. Then, the macroprudential stress tester can implement them consistently to predict the future.

The one-year ahead predicted values are close to the above reference values as shown in column 3 of Table $3-$ GDP growth is $5.28 \%$, for example. Notice, 
however, that equity return, inflation, and lending rate change experienced a decrease, as shown by their values of $4.48 \%, 4.26 \%$, and $-0.62 \%$, respectively. For the exchange rate change, the value is forecasted to reach $6.94 \%$, indicating a slight increase. Overall, there is no significant change in economic conditions at the end of the year.

Table 3.

\section{Historical, Predicted, and Stressed Values}

This table shows the result of historical, predicted and stressed values of five macroeconomic variables, consisting of inflation, lending rate, exchange rate, GDP, and equity price from January 2004 to December 2018 in year-over-year change. The historical value is defined as the average value of the macroeconomic variables calculated from time series arithmetic mean of monthly historical data. The predicted value is calculated as the iterated twelve period forecasts from monthly dependent variables. The stressed value can be obtained by taking the left (right) $1 \%$ to $10 \%$ tail distribution under the standard normal density function. All macroeconomic variables are measured in decimals.

\begin{tabular}{lccc}
\hline Macroeconomic Variable & Historical Value & Predicted Value & Stressed Value \\
\hline Inflation & 0.0611 & 0.0426 & 0.3397 \\
Lending rate & -0.0046 & -0.0062 & 0.0213 \\
Exchange rate & 0.0339 & 0.0694 & 0.2599 \\
GDP & 0.0538 & 0.0528 & -0.0299 \\
Equity Price & 0.1658 & 0.0448 & -0.5776 \\
\hline
\end{tabular}

In addition to the predicted normal macroeconomy, the predicted stress condition also needs to take the risks into account. Column 4 of Table 3 shows the predicted macroeconomic values under the stress condition using $1 \%-10 \%$ tail values of the forecast density. We see that the imposed shocks increased inflation rate change to $33.97 \%$, lending rate change to $2.13 \%$, and exchange rate change to $25.99 \%$, and decreased GDP growth to $2.99 \%$ and equity return to $57.76 \%$.

\section{B. Credit Risk Model and a Predicted Loan Growth}

The main innovation of our study is that it identifies the links between the macroeconomic scenarios and loan growth. We consider the sensitivity of credit risk to changing macroeconomic conditions through the credit risk regression model (see Section III), and the results are reported in Table 4.

Table 4 shows that the macroeconomic variable that has the closest relationship with loan growth is the exchange rate, meaning that an economic risk from exchange rate depreciation is the most significant driver of increases in loan growth. Statistically, this is indicated by the significant parameter estimate of the exchange rate. The coefficient estimate of the exchange rate change shows a positive sign of 0.1410 , meaning that a one per cent increase in the exchange rate increases loan growth by $14.10 \%$. 
Table 4.

\section{Loan growth regression results}

This table shows the results of loan growth regression estimation, with six selected variables. Data sample covers the period January 2004 to December 2018. The variables are: (i) Loan Growth, measured as the natural log of the amount of loans; (ii) Inflation, computed by the change during the past twelve months; (iii) Lending Rate, measured by the average of working capital, consumption and investment lending rate; (iv) Exchange Rate, computed by the natural log of the national currency to US dollar spot exchange rate for Indonesia (v) GDP, computed by the natural log of the seasonally adjusted GDP index with linear interpolation; (vi) Equity Price, measured as as the natural log of the JKSE stock price.All selected variables are in year-over-year change. The statistical significance at the 1\%, $\%$, and $10 \%$ levels are denoted by *****, and *, respectively.

\begin{tabular}{lcccc}
\hline Variable & Estimate & Standard Error & P-Value & [95\% Conf. Interval] \\
\hline Loan Growth & 0.9626 & $0.0353^{* * *}$ & 0.000 & {$[0.89291 .0323]$} \\
Inflation & 0.1076 & 0.1525 & 0.480 & {$[-0.19330 .4087]$} \\
Lending Rate & -0.7081 & 0.6581 & 0.282 & {$[-2.00710 .5908]$} \\
Exchange Rate & 0.1410 & $0.0665^{* *}$ & 0.034 & {$[0.00970 .2723]$} \\
GDP & -0.5938 & 1.0384 & 0.567 & {$[-2.64351 .4560]$} \\
Equity Price & -0.0205 & 0.0289 & 0.479 & {$[-0.07750 .0366]$} \\
Constant & 0.0245 & 0.0563 & 0.664 & {$[-0.08660 .1356]$} \\
\hline
\end{tabular}

\section{Main Output Indicator}

Thus, values of loan growth in normal and stress conditions can be predicted using the exchange rate change. By inputting the data on the systemic and idiosyncratic (grouped banks) components of credit risk, we can obtain the values of the systemic component of the predicted and stressed PDs, grouped banks' component of historical, predicted and stressed PDs, LGDs, expected losses and net losses. The details are presented in Appendices 3-5. All steps should be constructed coherently to achieve the main output indicator, which is the ERWCAR as exhibited in Table 5.

Table 5.

\section{Current Regulatory CAR and Historical ERW-CAR}

This table presents the aggregate CAR result for all banking system based on the current regulatory data and shows the stress testing result of the CAR under the consideration of economic risk from exchange rate shock in the historical observation as of December 2018. The current regulatory CAR and ERW-CAR are calculated by the median and mean value, while the standard deviation is used to capture the dispersion of the banks' CARs.

\begin{tabular}{lcc}
\hline Description & Current Regulatory CAR (\%) & ERW-CAR (\%) \\
\hline Mean & 22.82 & 20.31 \\
Median & 22.92 & 20.37 \\
Standard Deviation & 0.48 & 0.48 \\
\hline
\end{tabular}

Source: Indonesian Banking Statistics and Authors' Calculations

On the one hand, using the information gathered from Indonesian Banking Statistics (IBS) from December 2014 to December 2018, the regulatory CAR in the banking system, which does not reflect economic risks is $22.82 \%$ (on average) with a standard deviation of 0.48 indicating a significant dispersion of the regulatory CARs in the monthly basis. On the other hand, the ERW-CAR under historical scenario is $20.31 \%$ (on average), and is clearly lower than the current regulatory 
CAR. Compared to the current regulatory CAR, this means that the ERW-CAR can help banks allocate capital more optimally (i.e. in excess of $22.82 \%-20.31 \%=$ $2.51 \%$ ) to their business opportunities while maintaining the capital requirement.

In Table 6, we see that the ERW-CAR under a one-year ahead predicted scenario shows adequate safeguarding (i.e. ERW-CAR is approximately $20.08 \%$ ), meaning that, in the end of 2019, commercial banks in Indonesia will still have adequate capital to accommodate the regulatory requirement based on the macroprudential supervision. This predicted value also seems similar to the historical ERW-CAR under a single shock from exchange rate change.

Table 6.

\section{One-Year Ahead Predicted ERW-CAR and Stressed ERW-CAR}

This table presents the stress testing result of the CAR under the consideration of economic risk from exchange rate shock in the predicted and stress observations as of December 2019. The ERW-CARs are calculated by the median and mean value while the standard deviation is used to capture the dispersion of the banks'CARs.

\begin{tabular}{lcc}
\hline Description & Predicted ERW-CAR (\%) & Stressed ERW-CAR (\%) \\
\hline Mean & 20.08 & 18.22 \\
Median & 20.14 & 18.25 \\
Standard Deviation & 0.47 & 0.47 \\
\hline
\end{tabular}

Source: Authors' Calculations

In the stress observation, the value of ERW-CAR is still above the minimum requirement of capital regulation, at $18.22 \%$ on average. In addition, after accounting for a single economic risk from $25 \%$ of the exchange rate change, the ERW-CAR under predicted stress scenario is still capable of maintaining their capital. This means that if the banking system is predicted to experience a shock from a one quarter-exchange rate change year-on-year, their capital requirement is expected to go down around an average of $1.86 \%$.

These findings are in line with those of Buncic and Melecky's (2013), who found that the ERW-CARs of the banking systems in Eastern Europe are noticeably smaller than the regulatory CAR if calculated without economic risk considerations. It is also interesting to note that these results also strengthen the study of Indra (2018), which shows that the macroeconomic shock from exchange rate depreciation increases credit risk factor and loan performance in the Indonesian banking system. Further, once economic risk that stems from exchange rate depreciation is accounted for, Indonesian banks are capable of fulfilling the regulatory requirement of maintaining the CAR above eight per cent.

\section{V.CONCLUSION}

This study employs a macroeconomic approach to stress testing that captures credit risk. A credit risk regression model is required to link the credit risk measure to the macroeconomic variables. This is important since macroprudential regulators need to define adverse macroeconomic scenarios and then assess their effect on credit risk indicators. Another contribution of the study comes from its use of higher frequency data to cover more accurately the sensitivity of changes in 
the macroeconomic conditions, so that policymakers can enact the policy changes in a more timely and efficient manner. The outcome indicator, CAR, obtained from the improved model that considers the risk characteristics of the bank group and economic risks provides a robust measure of banking system stability relative to the traditional indicators. This indicator also provides a clearer picture regarding the link between macroprudential policy and the banking sector.

In short, using macroprudential stress-testing analysis, the value of the ERWCAR is below the current regulatory CAR. We can conclude that, after taking into account the economic risk from the exchange rate change, banks should be able to efficiently utilize their capital to take advantage of business opportunities. In the future normal economy, the ERW-CAR is close to the historical value, which means that the macroeconomic condition in one-year ahead does not experience a significant change. Under a one-year predicted stress condition, banks are designed to be invulnerable to shocks from exchange rate change. However, the ERW-CAR is well above the regulatory minimum (of eight per cent) by the end of 2019 and system still has a sufficient supply of bank capital. These findings are expected to help the Bank Indonesia, financial institutions, and macroprudential policymakers develop an informative alarm to anticipate the soundness of the financial system in the future.

\section{REFERENCES}

Alessandri, P., Gai, P., Kapadia, S., Mora, N., and Puhr, C. (2008). A Framework for Quantifying Systemic Stability, 1-46.

Allmen, U. E. von, and Hamann, J. (2017). Indonesia: Financial System Stability Assessment--Press Release and Statement by the Executive Director for Indonesia.

Altman, E. I., Resti, A., and Sironi, A. (2002). The Link between Default and Recovery Rates : Effects on the Procyclicality of Regulatory Capital Ratios. BIS Working Papers, 113.

BIS. (2006). Results of the fifth Quantitative Impact Study (QIS 5). Basel Committee on Banking Supervision.

Buncic, D., and Melecky, M. (2013). Macroprudential Stress Testing of Credit risk: A Practical Approach for Policy Makers. Journal of Financial Stability, 9, 347370. https://doi.org/10.1016/j.jfs.2012.11.003

Castrén, O., Dées, S., and Zaher, F. (2008). Global Macro-Financial Shocks and Expected Default Frequencies in the Euro Area. ECB Working Paper Series No. $875,1-42$.

Cihák, M. (2007). Introduction to Applied Stress Testing. IMF Working Papers, 07, 1. https://doi.org/10.5089/9781451866230.001

Coletti, D., Lalonde, R., Misina, M., Muir, D., and St-amant, P. (2008). Bank of Canada Participation in the 2007 FSAP Macro Stress-Testing Exercise. Financial System Review, 51-59.

Fiori, R., Foglia, A., and Iannotti, S. (2009). Beyond Macroeconomic Risk: the Role of Contagion in the Italian Corporate Default Correlation. Centre for Applied Research in Finance Working Paper, 91, 399-404.

Foglia, A. (2009). Stress Testing Credit Risk: A Survey of Authorities' Approaches. Ssrn, 9-45. https://doi.org/10.2139/ssrn.1396243 
GubernurBankIndonesia. (2005). Peraturan Bank Indonesia Nomor: 7/2/PBI/2005 Tentang Penilaian Kualitas Aktiva Bank Umum. Retrieved from www.bi.go.id Indra. (2018). Macro Stress Test Model Risiko Kredit: Studi Empiris Perbankan Konvensional dan Syariah di Indonesia. Jurnal Ekonomi Dan Kebijakan Publik, 9, 113-129.

Jimenez, G., \& Saurina, J. (2006). Credit Cycles, Credit Risk, and Prudential Regulation. International Journal of Central Banking, 2, 65-98. https:/doi. org/10.1227/01.NEU.0000349921.14519.2A

Lehmann, H., and Manz, M. (2006). The Exposure of Swiss Banks to Macroeconomic Shocks - an Empirical Investigation. Swiss National Bank Working Papers, (April).

Melecky, M., and Podpiera, A. M. (2012). Macroprudential Stress-Testing Practices of Central Banks in Central and Southeastern Europe: Comparison and Challenges Ahead. Emerging Markets Finance and Trade, 48, 118-134. https:// doi.org/10.2753/REE1540-496X480407

Newey, W. K., and West, K. D. (1987). A Simple, Positive Semi-Definite, Heteroskedasticity and Autocorrelation Consistent Covariance Matrix. Econometrica, 55, 703-708.

Onder, S., Damar, B., and Hekimoglu, A. A. (2016). Macro Stress Testing and an Application on Turkish Banking Sector1. Procedia Economics and Finance, 38, 17-37. https://doi.org/10.1016/S2212-5671(16)30173-3

Otoritas Jasa Keuangan. (2016a). Peraturan Otoritas Jasa Keuangan Nomor 6/ POJK.03/2016 Tentang Kegiatan Usaha dan Jaringan Kantor Berdasarkan Modal Inti Bank.

Otoritas Jasa Keuangan. (2016b). Siaran pers: Indonesia Siap Laksanakan Program Asesmen Sektor Keuangan. Retrieved from www.ojk.go.id 


\section{APPENDICES}

\section{Appendix 1 \\ Descriptive Statistics of Credit Risk and Macroeconomic Variables}

This table shows the descriptive statistics for variable of loan growth, inflation, lending rate, exchange rate, and GDP from January 2004 to December 2018. The selected variables are defined as follows: (i) loan growth, measured as the natural log of the amount of loans; (ii) inflation, computed by the change during the past twelve months; (iii) lending rate, measured by the average of working capital, consumption and investment lending rate; (iv) exchange rate, computed by the natural log of the national currency to US dollar spot exchange rate for Indonesia (v) GDP, computed by the natural log of the seasonally adjusted GDP index with linear interpolation; (vi) equity price, measured as as the natural log of the JKSE stock price. All selected variables are in year-over-year change.

\begin{tabular}{lccc}
\hline Variable & Mean & Median & St. Deviation \\
\hline Loan Growth & 0.1026 & 0.0562 & 0.2057 \\
Inflation & 0.0612 & 0.0582 & 0.0308 \\
Lending rate & -0.0046 & -0.0062 & 0.0110 \\
- Investment & -0.0045 & -0.0059 & 0.0112 \\
- Consumption & -0.0050 & -0.0054 & 0.0095 \\
- Working Capital & -0.0044 & -0.0065 & 0.0139 \\
Exchange rate & 0.0339 & 0.0319 & 0.0943 \\
GDP & 0.0538 & 0.0535 & 0.0061 \\
Equity price & 0.1658 & 0.1616 & 0.2581 \\
\hline
\end{tabular}

\section{Appendix 2 \\ Descriptive Statistics of Banking as Input of Output Indicators (in Billion Rupiah)}

This table shows the descriptive statistics of profit and loan loss reserves, classified based on core capital owned, regulatory capital and risk weighted asset, gathered aggregately from December 2014 to December 2018. Banks are grouped into four Business Activities (BA), consisting of Group of BA 1 (less than one trillion rupiah); Group of BA 2 (from one to less than five trillion rupiah); Group of BA 3 (from five to less than thirty trillion rupiah); and Group of BA 4 (at least thirty trillion rupiah). All selected variables are in billion rupiah.

\begin{tabular}{lccc}
\hline Variable & Mean & Median & St. Deviation \\
\hline Profit - BA 1 & 1,958 & 1,874 & 804 \\
Profit - BA 2 & 15,144 & 13,710 & 4,097 \\
Profit - BA 3 & 40,461 & 40,269 & 7,974 \\
Profit - BA 4 & 96,298 & 90,030 & 13,084 \\
Loan Loss Reserves - BA 1 & 2,087 & 2,056 & 332 \\
Loan Loss Reserves - BA 2 & 13,086 & 13,012 & 1,634 \\
Loan Loss Reserves - BA 3 & 32,002 & 31,372 & 4,135 \\
Loan Loss Reserves - BA 4 & 22,450 & 15,006 & 13,303 \\
Regulatory Capital & $1,102,863$ & $1,102,416$ & 92,512 \\
Risk Weighted Asset & $4,830,723$ & $4,792,679$ & 374,386 \\
\hline
\end{tabular}




\section{Appendix 3 \\ Descriptive Statistics of Systemic Component of Credit Risk (\%)}

This table shows the descriptive statistics of the aggregate level of PDs that present an exact value of each asset class under predicted and stressed observations over the sample period after the economic risk from exchange rate shock is considered. ${ }^{\mathrm{R}}$ Retail, ${ }^{\mathrm{b}} \mathrm{QRE}$ retail, ' $\mathrm{C}$ oans to public institutions and state-owned enterprises, ${ }^{\mathrm{d}}$ Loans to credit institutions.

\begin{tabular}{lcc}
\hline Asset Class & Predicted PDs & Stressed PDs \\
\hline Corporates & 1.5803 & 2.1719 \\
Small Medium Enterprises (SMEs) & 4.6333 & 6.3678 \\
Consumer Mortgage Loans & 19.0493 & 26.1806 \\
Consumer Loans & 12.1907 & 16.7544 \\
Other Consumer Loans & 6.6866 & 9.1898 \\
Sovereigns & 0.2580 & 0.3546 \\
Banks $^{\mathrm{d}}$ & 0.7955 & 1.0933 \\
\hline
\end{tabular}

\section{Appendix 4 \\ Descriptive Statistics of Grouped Banks' Component of Credit Risk (\%)}

This table shows the descriptive statistics of the aggregate level PDs and LGDs that presents the minimum, median and maximum under historical, predicted and stressed observations over sample period after economic risk from exchange rate shock is considered. aRetail, bQRE retail, cLoans to public institutions and state-owned enterprises, ${ }^{\mathrm{d}}$ Loans to credit institutions.

\begin{tabular}{|c|c|c|c|}
\hline Asset Class & Min & Median & Max \\
\hline \multicolumn{4}{|c|}{ Panel A: Historical Probabilities of Default } \\
\hline Corporates & 1.47 & 1.4737 & 1.57 \\
\hline Small Medium Enterprises (SMEs) ${ }^{a}$ & 4.31 & 4.3224 & 4.41 \\
\hline Consumer Mortgage Loans & 17.72 & 17.7214 & 17.82 \\
\hline Consumer Loans ${ }^{\mathrm{b}}$ & 11.34 & 11.3452 & 11.44 \\
\hline Other Consumer Loans & 6.22 & 6.2312 & 6.32 \\
\hline Sovereigns $^{c}$ & 0.24 & 0.2411 & 0.34 \\
\hline Banks $^{\mathrm{d}}$ & 0.74 & 0.74 & 0.84 \\
\hline \multicolumn{4}{|c|}{ Panel B: Predicted Probabilities of Default } \\
\hline Corporates & 1.5803 & 1.5840 & 1.6803 \\
\hline Small Medium Enterprises (SMEs) ${ }^{a}$ & 4.6333 & 4.6457 & 4.7333 \\
\hline Consumer Mortgage Loans & 19.0493 & 19.0508 & 19.1493 \\
\hline Consumer Loans ${ }^{\mathrm{b}}$ & 12.1907 & 12.1959 & 12.2907 \\
\hline Other Consumer Loans & 6.6866 & 6.6979 & 6.7866 \\
\hline Sovereigns $^{c}$ & 0.2580 & 0.2591 & 0.3580 \\
\hline Banks $^{\mathrm{d}}$ & 0.7955 & 0.7955 & 0.8955 \\
\hline \multicolumn{4}{|c|}{ Panel C: Stressed Probabilities of Default } \\
\hline Corporates & 2.1719 & 2.1756 & 2.2719 \\
\hline Small Medium Enterprises (SMEs) ${ }^{\mathrm{a}}$ & 6.3678 & 6.3802 & 6.4678 \\
\hline Consumer Mortgage Loans & 26.1806 & 26.1820 & 26.2806 \\
\hline Consumer Loans ${ }^{\mathrm{b}}$ & 16.7544 & 16.7596 & 16.8544 \\
\hline Other Consumer Loans & 9.1898 & 9.2010 & 9.2898 \\
\hline Sovereigns $^{c}$ & 0.3546 & 0.3557 & 0.4546 \\
\hline Banks $^{\mathrm{d}}$ & 1.0933 & 1.0933 & 1.1933 \\
\hline
\end{tabular}


Appendix 4

Descriptive Statistics of Grouped Banks' Component of Credit Risk (\%) (Continued)

\begin{tabular}{|c|c|c|c|}
\hline Asset Class & Min & Median & Max \\
\hline \multicolumn{4}{|c|}{ Panel D: Historical Losses Given Default } \\
\hline Corporates & 35.2 & 35.2179 & 35.6789 \\
\hline Small Medium Enterprises (SMEs) ${ }^{\mathrm{a}}$ & 49.6 & 49.6284 & 49.8302 \\
\hline Consumer Mortgage Loans & 40.4 & 40.4006 & 40.4456 \\
\hline Consumer Loans ${ }^{\mathrm{b}}$ & 55.7 & 55.7051 & 55.7982 \\
\hline Other Consumer Loans & 45.1 & 45.1163 & 45.2450 \\
\hline Sovereigns $^{c}$ & 38.2 & 38.2361 & 41.3833 \\
\hline Banks ${ }^{\mathrm{d}}$ & 39.4 & 39.4 & 40.4649 \\
\hline \multicolumn{4}{|c|}{ Panel E: Predicted Losses Given Default } \\
\hline Corporates & 35.7281 & 35.7461 & 36.2070 \\
\hline Small Medium Enterprises (SMEs) ${ }^{a}$ & 50.3442 & 50.3726 & 50.5744 \\
\hline Consumer Mortgage Loans & 41.0061 & 41.0068 & 41.0517 \\
\hline Consumer Loans ${ }^{\mathrm{b}}$ & 56.5357 & 56.5408 & 56.6339 \\
\hline Other Consumer Loans & 45.7767 & 45.7930 & 45.9217 \\
\hline Sovereigns $^{c}$ & 38.7731 & 38.7731 & 41.9565 \\
\hline Banks $^{\mathrm{d}}$ & 39.9911 & 39.9911 & 41.0560 \\
\hline \multicolumn{4}{|c|}{ Panel F: Stressed Losses Given Default } \\
\hline Corporates & 43.6033 & 43.6481 & 44.8006 \\
\hline Small Medium Enterprises (SMEs) ${ }^{\mathrm{a}}$ & 61.4410 & 61.5122 & 62.0164 \\
\hline Consumer Mortgage Loans & 50.0447 & 50.0463 & 50.1587 \\
\hline Consumer Loans ${ }^{\mathrm{b}}$ & 68.9973 & 69.0099 & 69.2428 \\
\hline Other Consumer Loans & 55.8667 & 55.9075 & 56.2293 \\
\hline Sovereigns $^{c}$ & 47.3195 & 47.4096 & 55.2778 \\
\hline Banks $^{\mathrm{d}}$ & 48.8059 & 48.8060 & 51.4681 \\
\hline
\end{tabular}

\section{Appendix 5. \\ Descriptive Statistics of Net Losses (in Billion Rupiah)}

This table shows the descriptive statistics of net lossses classified based on core capital owned. Banks are grouped into four Business Activities (BA), consisting of Group of BA 1 (less than one trillion rupiah); Group of BA 2 (from one to less than five trillion rupiah); Group of BA 3 (from five to less than thirty trillion rupiah); and Group of BA 4 (at least thirty trillion rupiah). This table presents the average, median and standard deviation under historical, predicted and stressed observations over the sample period after economic risk from exchange rate shock is considered.

\begin{tabular}{lccc}
\hline Description & $\begin{array}{c}\text { Historical Net } \\
\text { Losses }\end{array}$ & Predicted Net Losses & Stressed Net Losses \\
\hline Mean - BA 1 & 1,509 & 1,646 & 2,762 \\
Median - BA 1 & 1,282 & 1,398 & 2,345 \\
St. Deviation - BA 1 & 425 & 463 & 778 \\
Mean - BA 2 & 14,756 & 16,101 & 27,004 \\
Median - BA 2 & 14,613 & 15,944 & 26,742 \\
St. Deviation - BA 2 & 709 & 774 & 1,299 \\
Mean - BA 3 & 44,010 & 48,019 & 80,537 \\
Median - BA 3 & 42,723 & 46,619 & 78,195 \\
St. Deviation - BA 3 & 3,302 & 3,598 & 6,029 \\
Mean - BA 4 & 61,205 & 66,765 & 111,955 \\
Median - BA 4 & 63,086 & 68,798 & 115,348 \\
St. Deviation - BA 4 & 8,331 & 9,088 & 15,239 \\
\hline
\end{tabular}


This page is intentionally left blank 